\title{
Analisis Faktor Yang Mempengaruhi Minat Berkunjung Ulang Pasien ke Poliklinik Spesialis di RSI Ibnu Sina Padang (BPJS Kesehatan)
}

\author{
Laiza Faaghna ${ }^{1}$, Ratni Prima Lita $^{2}$, Rima Semiarty ${ }^{3}$
}

\begin{abstract}
Abstrak
Rumah sakit merupakan fasilitas pelayanan kesehatan sekunder setelah masyarakat mendapatan pelayanan kesehatan primer di puskesmas, klinik utama, klinik pratama ataupun praktek dokter untuk dapat melayani pengobatan lanjutan terutama yang terkait dengan pelayanan spesialis, sub spesialis dan pemeriksaan penunjang medik lainnya. Saat ini di BPJS Kesehatan kota Padang telah terdaftar menjadi peserta JKN-KIS mencapai 1.463.097 jiwa atau $70,53 \%$ dari jumlah penduduk. Pada era persaingan ini, masyarakat dapat memilih rumah sakit untuk berkunjung kembali sesuai dengan minat pasien, dengan melakukan penilaian melalui sikap pasien terhadap lingkungan, citra merek yang melekat, nilai yang dirasakan, persepsi terhadap kualitas pelayanan. Tujuan penelitian ini adalah menentukan faktor yang mempengaruhi minat berkunjung ulang pasien ke poliklinik spesialis RSI Ibnu Sina Padang. Penelitian ini dilakukan dengan desain cross sectional, yaitu analisis kuantitatif. Hasil penelitian menunjukkan bahwa variabel sikap pasien, citra merek, persepsi nilai, persepsi kualitas berpengaruh secara signifikan terhadap minat berkunjung ulang pasien ke poliklinik spesialis RSI Ibnu Sina Padang (CR >1,96, $p<0,05$.
\end{abstract}

Kata kunci: sikap pasien, citra merek, persepsi nilai, persepsi kualitas, minat berkunjung ulang

\begin{abstract}
The hospital is a secondary health care facility after the community has received primary health care in a health center, main clinic, pre-primary clinic or doctor's practice to be able to serve further treatment, especially those related to specialist services, sub-specialists and other medical examinations. At present, JKN-KIS participants reaching $1,463,097$ people or $70.53 \%$ of the total population in Padang. In this competition era, the community can choose a hospital to visit again according to the interests of the patient, by evaluating the patient's attitude towards the environment, the brand image that is inherent, perceived value, perception of service quality. The objective of this study was to determine the factors that influence the interest in repurchase intention to the specialist polyclinic RSI Ibnu Sina Padang. This research was conducted with causal design, namely quantitative analysis. The results showed that the variables of patient attitudes, brand image, perceived value, perceived quality significantly affected the interest in repurchase intention to the specialist polyclinic $(C R>1.96, p$ value $<0.05$.
\end{abstract}

Keywords: patient attitude, brand image, perceived value, perceived quality, re-purchase intention

Affiliasi penulis: 1. RSI Ibnu Sina Padang, 2. Departemen Manajemen, Fakultas Ekonomi Universitas Andalas, 3. Bagian IImu Kesehatan Masyarakat, Fakultas Kedokteran Universitas Andalas Korespondensi: Ratni Prima Lita, Email; ratni31@yahoo.com Telp: 081374460561

\section{PENDAHULUAN}

Rumah sakit merupakan fasilitas pelayanan kesehatan sekunder setelah masyarakat mendapatan pelayanan kesehatan primer di puskesmas, klinik utama, klinik pratama ataupun praktek dokter untuk dapat melayani pengobatan lanjutan terutama yang terkait dengan pelayanan spesialis, sub spesialis dan pemeriksaan penunjang medik lainnya. ${ }^{1}$

Pemerintah terus meningkatkan kerjasama dengan seluruh pelayanan kesehatan rumah sakit sebagai fasilitas kesehatan rujukan peserta Jaminan 
Kesehatan Nasional (JKN) pada tahun 2017 mencapai 2.513 rumah sakit yang telah bekerjasama dengan BPJS Kesehatan. Rumah sakit swasta merupakan sarana pelayanan terbesar yang bekerjasama dengan BPJS Kesehatan yaitu 48,2\% (1.212 rumah sakit swasta). ${ }^{2}$

Kota Padang merupakan salah satu kota yang ikut menyukseskan program Pemerintah untuk dapat memberikan pelayanan kesehatan kepada seluruh masyarakat. Kota Padang memiliki 29 rumah sakit yaitu 6 rumah sakit pemerintah, 7 rumah sakit swasta (umum), 16 rumah sakit khusus. Seluruh rumah sakit telah bekerjasama dengan BPJS Kesehatan. Saat ini di BPJS Kesehatan kota Padang telah terdaftar menjadi peserta JKN-KIS mencapai 1.463.097 jiwa atau $70,53 \%$ dari jumlah penduduk. ${ }^{2}$

RSI Ibnu Sina merupakan rumah sakit kelas C yang melayani poliklinik spesialis/sub spesialis, rawat inap dan pemeriksaan penunjang medik lainnya. Merupakan salah satu rumah sakit swasta yang menerima rujukan fasilitas pelayanan sekunder kedua (Faskes Tingkat 2), yang telah bekerjasama dengan PT. Askes (Persero) dan BPJS Kesehatan sejak tahun 2006 hingga saat ini. Rata - rata perhari melayani pasien poliklinik 380 pasien/hari. $^{3}$

Persaingan yang terjadi terhadap peminatan pasien untuk memilih rumah sakit swasta sebagai sarana pelayanan kesehatan dapat dipengaruhi oleh sikap pasien terhadap rumah sakit, citra merek, persepsi nilai, persepsi kualitas. ${ }^{4,5,6}$

Peminatan berkunjung pasien untuk memilih pelayanan poliklinik spesialis RSI Ibnu Sina Padang sebagai sarana pelayanan belum pernah dilakukan, oleh karena perlu dilakukan penelitian mengenai faktor apa saja yang mempengaruhi minat untuk kembali berkunjung ke pelayanan poliklinik spesialis. Perlu dilakukan penelitian untuk mengetahui faktor - faktor apa saja yang menjadi minat pasien untuk berkunjung ulang ke poliklinik spesialis, dan diharapkan bisa sebagai rujukan manajemen dalam pengambilan kebijakan sehingga berdampak pada pelayanan kepada pasien yang lebih baik.

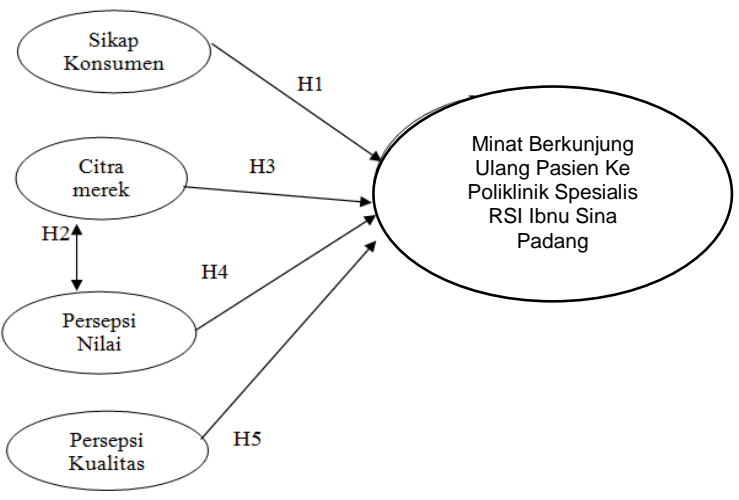

Gambar 1. Kerangka konsep penelitian

\section{METODE}

Ini adalah penelitian kausal, yaitu desain yang digunakan untuk mengidentifikasi hubungan sebab akibat antara variabel independen dengan variabel dependen. Penelitian ini dilakukan pada bulan Juli sampai dengan Agustus tahun 2018, di poliklinik spesialis RSI Ibnu Sina Padang.

Sampel dalam penelitian ini adalah pasien poliklinik spesialis yang menggunakan jaminan BPJS Kesehatan, ditentukan dengan rumus slovin sebesar 384 responden. Untuk penentuan besar sampel pada setiap poliklinik spesialis dilakukan dengan alokasi proposional agar sampel yang diambil lebih proporsional. Metode pengambilan sampel digunakan random block sampling.

Data primer diperoleh melalui hasil penyebaran kuesioner kepada responden, data sekunder merupakan informasi pendukung antara lain profil dan pertumbuhan kunjungan pasien poliklinik spesialis RSI Ibnu Sina Padang.

Instrumen penelitian menggunakan skala likert, skala 1 - 5 (sangat tidak setuju, tidak setuju, biasa saja, setuju, sangat setuju). Data dianalisa dengan menggunakan metode analisis Stuctural Equation Modelling (SEM) dengan bantuan program AMOS versi 2.0. SEM dapat dideskripsikan sebagai suatu analisis yang menggabungkan pendekatan analisis faktor (factor analysis), model structural (structural mode), dan analisis jalur (path analysis). SEM merupakan gabungan dari metode statistik yang 
terpisah yaitu analisis faktor (factor analysis) serta model persamaan simultan (simultaneous equation modeling). Uji validitas digunakan untuk mengukur sah atau valid tidaknya suatu kuesioner. Suatu kuesioner dikatakan valid jika pertanyaan dalam kuesiner mampu untuk mengungkapkan sesuatu yang akan diukur oleh kuesioner tersebut. Jika loading factor > 0,50 maka dapat dikatakan valid. Uji reliabilitas dalam SEM dapat diperoleh melalui Construct Reliability $>0,70$. Pemilihan teknik analisis SEM dalam penelitian ini sesuai dengan tujuan penelitian yaitu menganalisis indikator yang berpengaruh terhadap minat berkunjung pasien ke poliklinik spesialis RSI Ibnu Sina Padang. Penelitian ini akan menggunakan dua macam teknik analisis yaitu: (1) Analisis faktor konfirmatori (Confirmatory Factor) pada SEM yang digunakan mengkonfirmasikan faktor-faktor yang paling dominan dalam satu kelompok variabel yaitu konstruk eksogen dan konstruk endogen. (2) Regression Weight yang yang digunakan meneliti besarnya sikap pasien, citra merek, persepsi nilai, persepsi kualitas dan minat berkunjung pasien ke poliklinik spesialis RSI Ibnu Sina Padang. Uji ini digunakan untuk menguji hipotesis 1 sampai dengan hipotesis $5 .^{7}$

\section{HASIL}

Penelitian ini merupakan studi kuantitatif yang dilakukan dengan cara penyebaran kuesioner terhadap pasien di poliklinik spesialis RSI Ibnu Sina Padang. Hasil distribusi frekuensi dari variabel penelitian sebagai berikut:

Tabel 1. Distribusi frekuensi berdasarkan variabel penelitian

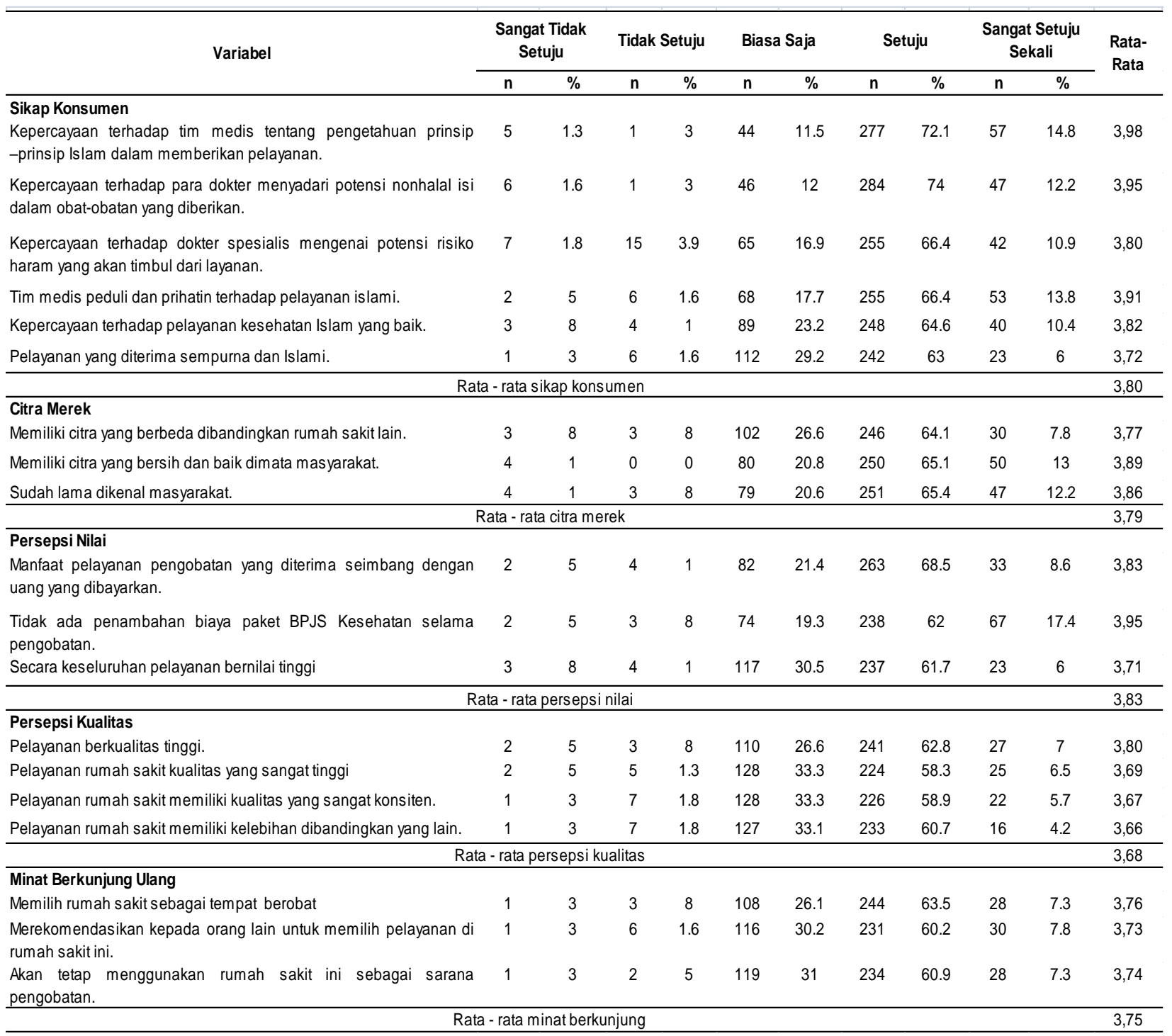


Rata-rata penilaian responden terhadap penilaian sikap pasien sebesar 3,80 (setuju), citra merek rata-rata 3,79 (setuju), persepsi nilai rata-rata 3,83 (setuju), persepsi kualitas rata-rata 3,68 (setuju), minat berkunjung pasien rata-rata 3,75 (setuju). Ratarata penilaian pasien terhadap pelayanan yang diberikan poliklinik spesialis RSI Ibnu Sina Padang tertinggi pada penilaian sikap pasien baik $(3,98)$ terhadap kepercayaan pasien kepada tim medis tentang pengetahuan prinsip Islam dalam memberikan pelayanan. Rata-rata penilaian terendah dinilai pada persepsi kualitas $(3,66)$ terhadap pelayanan rumah sakit memiliki kelebihan dibandingkan dengan rumah sakit lainnya.

Tabel 2. Uji reliability dan variance extract

\begin{tabular}{|c|c|c|c|c|c|c|c|}
\hline Variabel & Loading & Loading $^{2}$ & Error & 1-Error & $\begin{array}{c}(\Sigma \\
\text { Loading }^{2} \\
\end{array}$ & Reliabel & $\begin{array}{c}\text { Variance } \\
\text { Extract }\end{array}$ \\
\hline \multicolumn{8}{|c|}{ Consumer's Attitude } \\
\hline ca1 & 0,71 & 0,5673 & 0,57 & 0,45 & 16.956 & 0,8698 & 0,669 \\
\hline ca2 & 0,83 & 0,7908 & 0,80 & 0,56 & & & \\
\hline ca3 & 0,75 & 0,6785 & 0,69 & 0,53 & & & \\
\hline ca4 & 0,77 & 0,6530 & 0,65 & 0,46 & & & \\
\hline $\mathrm{ca} 5$ & 0,91 & 0,8354 & 0,83 & 0,55 & & & \\
\hline $\mathrm{ca6}$ & 0,72 & 0,6732 & 0,68 & 0,49 & & & \\
\hline \multicolumn{8}{|c|}{ Brand Image } \\
\hline bi7 & 0,89 & 0,7993 & 0,80 & 0,55 & 4.835 & 0,8920 & 0,6485 \\
\hline bi8 & 0,78 & 0,6421 & 0,64 & 0,43 & & & \\
\hline bi9 & 0,77 & 0,5443 & 0,54 & 0,44 & & & \\
\hline \multicolumn{8}{|c|}{ Perceived Value } \\
\hline pv10 & 0,70 & 0,6587 & 0,66 & 0,48 & 5.446 & 0,8205 & 0,6936 \\
\hline pv11 & 0,81 & 0,7324 & 0,73 & 0,32 & & & \\
\hline pv12 & 0,87 & 0,7445 & 0,75 & 0,49 & & & \\
\hline \multicolumn{8}{|c|}{ Perceived Quality } \\
\hline $\mathrm{pq} 13$ & 0,76 & 0,5671 & 0,57 & 0,45 & 9.407 & ' 0,8607 & 0,6721 \\
\hline $\mathrm{pq} 14$ & 0,77 & 0,6616 & 0,66 & 0,49 & & & \\
\hline $\mathrm{pq} 15$ & 0,88 & 0,7613 & 0,76 & 0,42 & & & \\
\hline $\mathrm{pq} 16$ & 0,76 & 0,6137 & 0,61 & 0,22 & & & \\
\hline \multicolumn{8}{|c|}{ Purchase Intention } \\
\hline pi17 & 0,87 & 0,7731 & 0,77 & 0,55 & 5.104 & 0,8457 & 0,6598 \\
\hline pi18 & 0,86 & 0,7260 & 0,73 & 0,52 & & & \\
\hline pi19 & 0,77 & 0,5641 & 0,56 & 0,36 & & & \\
\hline
\end{tabular}

Berdasarkan pengamatan pada Tabel 2 tampak bahwa tidak terdapat nilai reliabilitas yang lebih kecil dari 0,70 . Begitu pula pada uji variance extract juga tidak ditemukan nilai yang berada dibawah 0,50 . Hasil pengujian ini menunjukkan semua indikator-indikator observed) pada konstruk (sikap pasien, citra merk, persepsi kualitas dan persepsi nilai) yang dipakai sebagai observed bagi konstruk atauvariabel yang diteliti sehingga mampu menjelaskan konstruk atau variabel laten yang dibentuknya.

Matrik input yang digunakan sebagai input adalah matrik kovarians, untuk menguji suatu hubungan kausalitas maka matrik kovarian yang dijadikan sebagai input. Dari hasil pengolahan data yang dikumpulkan, matrik kovarian data yang digunakan tertuang dalam Tabel 3 berikut:

Tabel 3. Matrik kovarian

\begin{tabular}{|c|c|c|c|c|c|c|c|c|c|c|}
\hline & pi19 & pi18 & pi17 & $\mathrm{pa} 16$ & $\mathrm{pa} 15$ & pa14 & pe13 & pv12 & pvi11 & $\mathrm{pv} 10$ \\
\hline pi19 & 2,514 & & & & & & & & & \\
\hline pi18 & 2,123 & 3,013 & & & & & & & & \\
\hline pi17 & 1,619 & 1,590 & 2,971 & & & & & & & \\
\hline $\mathrm{pq} 16$ & 1,547 & 1,732 & 1,740 & 2,198 & & & & & & \\
\hline $\mathrm{pq} 15$ & 1,590 & 1,269 & 1,352 & 1,119 & 2,669 & & & & & \\
\hline $\mathrm{pq} 14$ & 1,502 & 0,977 & 1,590 & 1,732 & 2,563 & 2,769 & & & & \\
\hline $\mathrm{pq} 13$ & 1,732 & 1,480 & 0,895 & 1,269 & 1,590 & 1,909 & 2,871 & & & \\
\hline pv12 & 1,309 & 1,590 & 1,073 & 1,019 & 1,419 & 1,269 & 1,732 & 2,562 & & \\
\hline pv11 & 1,420 & 1,352 & 1,269 & 1,587 & 0,956 & 1,274 & 1,590 & 1,344 & 2,556 & \\
\hline pv10 & 1,345 & 1,239 & 1,076 & 1,590 & 1,672 & 1,312 & 1,445 & 1,269 & 1,590 & 2,908 \\
\hline & $\underline{b i g}$ & $\underline{b i 8}$ & $\underline{b i 7}$ & $\underline{\mathrm{Ca}}$ & $\underline{\text { ca5 }}$ & cat & $\underline{\mathrm{Ca} 3}$ & $\underline{\mathrm{Ca} 2}$ & $\underline{\text { cal }}$ & \\
\hline big & 2,019 & & & & & & & & & \\
\hline bi8 & 2,088 & 2,392 & & & & & & & & \\
\hline bi7 & 1,732 & 1,992 & 2,734 & & & & & & & \\
\hline$c a 6$ & 1,269 & 1,590 & 2,220 & 2,681 & & & & & & \\
\hline$c 25$ & 1,350 & 1,480 & 1,732 & 1,732 & 2,415 & & & & & \\
\hline ca4 & 1,829 & 1,076 & 1,569 & 1,269 & 1,019 & 2,109 & & & & \\
\hline $\mathrm{Ca} 3$ & 0,909 & 1,019 & 0,895 & 1,590 & 1,344 & 1,732 & 2,145 & & & \\
\hline $\mathrm{Ca}$ & 1,590 & 1,269 & 1,344 & 0,956 & 1,480 & 1,269 & 1,312 & 2,762 & & \\
\hline cal & 1,303 & 1,200 & 1,480 & 1,312 & 1,350 & 1,019 & 1,590 & 1,076 & 2,667 & \\
\hline
\end{tabular}

Analisis Structural Equation Model (SEM) secara full model yang bertujuan untuk menguji model dan hipotesis yang telah dikembangkan dalam penelitian. Pengujian model dalam structural equation model dilakukan dengan dua pengujian, yaitu uji kesesuaian model dan uji signifikasi kausalitas melalui uji koofisien regresi. Hasil pengolahan data untuk analisis SEM sebagai berikut: 


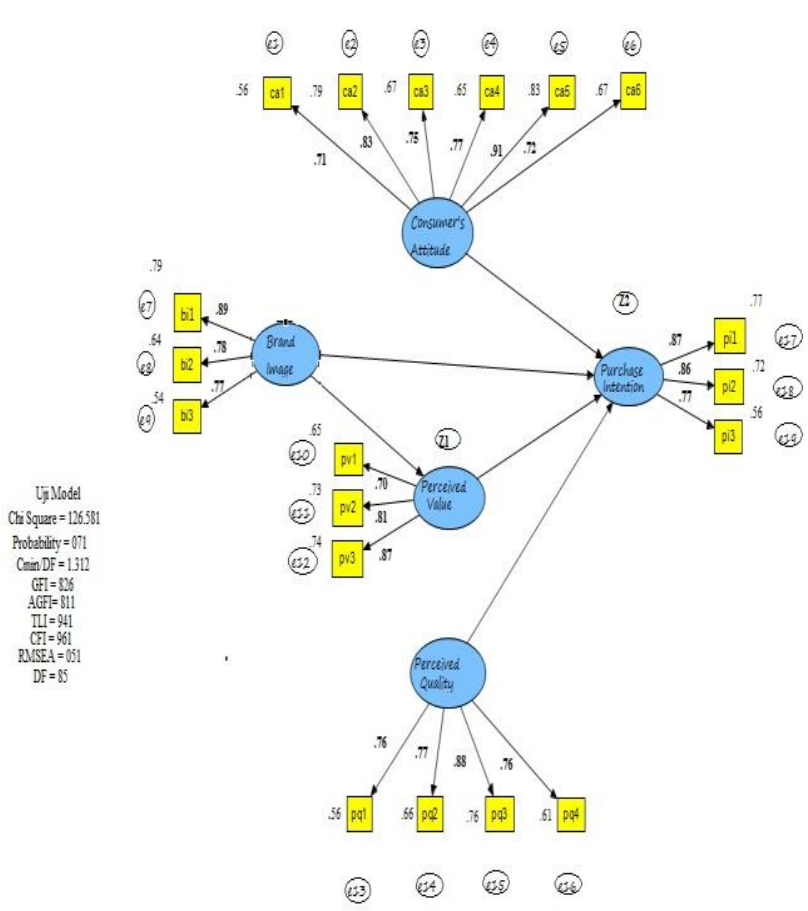

Gambar 2. Hasil uji structural equation model (SEM)

Tabel 4. Hasil regression weights analisis structural equation modelling

\begin{tabular}{llllllll}
\hline & & & Estimate & S.E & C.R & P & Label \\
\hline $\mathrm{PI}$ & $<--$ & Consumer's Attitude & 0,487 & 0,170 & 2,420 & 0,013 & par_13 \\
\hline $\mathrm{PV}$ & $<--$ & Brand Image & 0,561 & 0,153 & 2,715 & 0,012 & par_17 \\
\hline $\mathrm{PI}$ & $<--$ & Brand Image & 0,530 & 0,139 & 2,691 & 0,009 & par_14 \\
\hline $\mathrm{PI}$ & $<--$ & Perceived Value & 0,380 & 0,142 & 2,827 & 0,016 & par_15 \\
\hline $\mathrm{PI}$ & $<--$ & Perceived Quality & 0,582 & 0,125 & 2,990 & 0,010 & par_16 \\
\hline ca1 & $<--$ & Consumer's Attitude & 1,000 & & & & \\
\hline ca2 & $<--$ & Consumer's Attitude & 1,055 & 0,112 & 7,168 & 0,000 & par_1 \\
\hline ca3 & $<--$ & Consumer's Attitude & 1,983 & 0,162 & 8,921 & 0,000 & par_2 \\
\hline ca4 & $<--$ & Consumer's Attitude & 1,498 & 0,124 & 9,173 & 0,000 & par_3 \\
\hline ca5 & $<--$ & Consumer's Attitude & 1,078 & 0,112 & 7,941 & 0,000 & par_4 \\
\hline ca6 & $<--$ & Consumer's Attitude & 1,035 & 0,138 & 7,798 & 0,000 & par_5 \\
\hline bi7 & $<--$ & Brand Image & 1,000 & & & & \\
\hline bi8 & $<--$ & Brand Image & 0,923 & 0,138 & 7,327 & 0,000 & par_6 \\
\hline bi9 & $<--$ & Brand Image & 1,890 & 0,156 & 7,098 & 0,000 & par_7 \\
\hline pv10 & $<--$ & Perceived Value & 1,000 & & & & \\
\hline pv11 & $<--$ & Perceived Value & 1,451 & 0,174 & 8,921 & 0,000 & par_8 \\
\hline pv12 & $<--$ & Perceived Value & 0,961 & 0,187 & 7,941 & 0,000 & par_9 \\
\hline pq13 & $<--$ & Perceived Quality & 1,000 & & & & \\
\hline pq14 & $<--$ & Perceived Quality & 1,713 & 0,128 & 9,946 & 0,000 & par_10 \\
\hline pq15 & $<--$ & Perceived Quality & 1,274 & 0,145 & 8,931 & 0,000 & par_11 \\
\hline pq16 & $<--$ & Perceived Quality & 1,146 & 0,172 & 7,798 & 0,000 & par_12 \\
\hline & & & & & & & \\
\hline
\end{tabular}

Pada tabel 4 terlihat bahwa setiap indikator pembentuk variabel laten menunjukkan hasil yang memenuhi kriteria yaitu nilai $C R>1,96$ dengan $p$ value $<0,05$ dan nilai lamda atau loading factor $>0,5$. Ini berarti model yang dipakai dalam penelitian ini dapat diterima. Evaluasi goodness of fit bertujuan untuk menilai seberapa baik model penelitian yang dikembangkan. Pada tahapan ini kesesuaian model penelitian dievaluasi di tingkat goodness of fit, namun yang perlu dilakukan sebelumnya adalah mengevaluasi data yang digunakan agar dapat memenuhi kriteria yang diisyaratkan oleh SEM.

Tabel 5. Indeks pengujian kelayakan model penelitian

\begin{tabular}{lccc}
\hline \begin{tabular}{c} 
Kriteria \\
Goodness of \\
\multicolumn{1}{c}{ Fit }
\end{tabular} & Cut Of Value & Hasil & Evaluasi \\
\hline Chi-Square & $\mathrm{X}^{2}$ dengan df: 8 & 5,912 & Baik \\
& $\mathrm{p}: 5 \%=14,602$ & & \\
Probability & $\geq 0,05$ & 0,671 & Baik \\
GFI & $\geq 0,90$ & 0,913 & Baik \\
AGFI & $\geq 0,90$ & 0,952 & Baik \\
TLI & $\geq 0,95$ & 1,129 & Baik \\
CFI & $\geq 0,95$ & 1,001 & Baik \\
CMIN/DF & $\leq 2,00$ & 0,801 & Baik \\
RMSEA & $\leq 0,08$ & 0,012 & Baik \\
\hline
\end{tabular}

Pengujian hipotesis dilakukan dengan cara menganalisis nilai Critical Ratio (CR) dan nilai probability $(\mathrm{P})$ hasil olah data, dibandingkan dengan batasan statistik yang diisyaratkan, yaitu diatas 1,96 untuk nilai CR dan dibawah 0,05 untuk nilai $p$ value. Secara rinci pengujian hipotesis sebagai berikut:

\section{Uji Hipotesis 1}

Hasil uji hipotesis 1 (satu) menunjukkan terdapat pengaruh yang signifikan antara variabel sikap pasien terhadap minat berkunjung ulang pasien ke poliklinik spesialis RSI Ibnu Sina Padang $(C R=2,420, p=$ 0,013).

\section{Uji Hipotesis 2}

Hasil uji hipotesis 2 (dua) menunjukkan terdapat pengaruh yang signifikan antara variabel citra merek terhadap nilai yang dirasakan pasien $(C R=2,715, p=$ 0,012).

\section{Uji Hipotesis 3}

Hasil uji hipotesis 3 (tiga) menunjukkan terdapat pengaruh yang signifikan antara variabel citra merek terhadap minat berkunjung ulang pasien ke poliklinik spesialis RSI Ibnu Sina Padang (CR =2,691, $\mathrm{p}=$ 0,009). 


\section{Uji Hipotesis 4}

Hasil uji hipotesis 4 (empat) menunjukkan terdapat pengaruh yang signifikan antara variabel persepsi nilai terhadap minat berkunjung ulang pasien ke poliklinik spesialis RSI Ibnu Sina Padang $(C R=2,827, \quad p=$ 0,016).

\section{Uji Hipotesis 5}

Hasil uji hipotesis 5 (lima) menunjukkan terdapat pengaruh yang signifikan antara variabel persepsi kualitas terhadap minat berkunjung ulang pasien ke poliklinik spesialis RSI Ibnu Sina Padang $(C R=2,990$, $p=0,010)$.

\section{PEMBAHASAN}

\section{Sikap Pasien Terhadap Minat Berkunjung Ulang Pasien ke Poliklinik Spesialis RSI Ibnu Sina Padang}

Sikap (attitude) merupakan suatu mental dan syarat sehubungan dengan kesiapan untuk menanggapi, diorganisasi melalui pengalaman dan memilki pengaruh yang mengarahkan dan atau dinamis terhadap perilaku. ${ }^{8}$ Sikap dapat diartikan sebagai cara kita berfikir, merasakan dan bertindak terhadap beberapa aspek.

Tingkat kepercayaan pasien terhadap tenaga medis yang terdiri dari dokter spesialis/subspesialis dan perawat tentang pengetahuan prinsip-prinsip Islam dalam memberikan pelayanan. Sikap yang ditunjukkan oleh pasien mencerminkan pengetahuan yang baik tentang prinsip pelayanan secara Islami yang diberikan saat pelayanan sebesar $86,9 \%$. Beberapa fenomena yang relatif baru antara umat Islam adalah memilih tempat mana yang berlabelkan Islam sebagai perawatan kesehatan sehingga mereka dapat yakin bahwa layanan kesehatan sesuai dengan ajaran syariah Islam. ${ }^{9}$

Sikap pasien terhadap dokter spesialias/ subspesialis adanya potensi non halal dalam obatobatan yang diberikan kepada pasien sebesar $86,2 \%$. Kepercayaan kehalalan terhadap isi obat ditunjukkan dengan adanya penjelasan oleh dokter spesialis/ subspesialis bahwa obat yang diberikan tidak mengandung unsur non halal. Kepercayaan oleh pasien terhadap pelayanan di RSI Ibnu Sina Padang Islami. Semakin tinggi sikap kepercayaan konsumen terhadap pelayanan kesehatan Islam yang diberikan maka semakin tinggi minat berkunjung pasien ke poliklinik spesialis RSI Ibnu Sina Padang.

Pelayanan yang diterima oleh umat Islam harus bersih, alami dan hiegenis dan tentunya harus halal, dalam beberapa kasus tertentu obat yang dikonsumsi dan tersedia juga tidak menimbulkan risiko bahaya dan kematian. ${ }^{10}$

Sikap pasien terhadap minat berkunjung ulang pasien ke poliklinik spesialis, RSI Ibnu Sina Padang perlu menggali, mengenali dan mampu menentukan dengan tepat apa yang sebenarnya menjadi sumber keunggulan di poliklinik spesialis dibandingkan dengan rumah sakit lainnya dalam menarik minat berkunjung ulang pasien ke poliklinik spesialis RSI Ibnu Sina.

\section{Citra Merek Terhadap Persepsi Nilai Pasien di Poliklinik Spesialis RSI Ibnu Sina Padang}

Citra merek (brand image) adalah persepsi tentang merek yang merupakan refleksi memori konsumen akan asosiasinya pada merek tersebut. Citra merek merupakan bagian dari merek yang dapat dikenali namun tidak dapat diucapkan seperti lambang, desain huruf atau warna khusus atau persepsi pelanggan atas sebuah produk atau jasa yang diwakili mereknya. ${ }^{11}$

Citra merek Yarsi dan RSI Ibnu Sina Padang sudah lama dikenal masyarakat sebesar $77,6 \%$, terdapat $22,4 \%$ pasien yang tidak begitu mengenal Yarsi dan RSI Ibnu Sina Padang. Citra merek atas nama Yarsi dinilai bersih dan baik terhadap RSI Ibnu Sina Padang sebesar $78,1 \%$, dan penilaian terhadap citra merek biasa saja dan tidak setuju sebesar $21,8 \%$. Perbedaan citra RSI Ibnu Sina Padang dengan rumah sakit swasta lainnya ditunjukkan sebesar $71,9 \%$, dan sebesar 28,1\%. Hal ini memberikan pemahaman bahwa citra rumah sakit Islam yang dimiliki oleh RSI Ibnu Sina sangat mempengaruhi persepsi nilai pasien. Citra rumah sakit Islam menjadi karakter khas sehingga konsumen dengan mudah membedakannya dengan rumah sakit lain dan menghasilkan persepsi nilai yang positif dari pasien.

Beberapa hasil penelitian sebelumnya menyatakan bahwa pasien berminat untuk memanfaatkan kembali pelayanan rumah sakit, karena 
memiliki persepsi nilai yang baik. Diukur melalui pelayanan petugas, mutu pelayanan yang diterima, serta kelengkapan sarana dan prasarana. ${ }^{12,13,14}$

\section{Citra Merek Terhadap Minat Berkunjung Ulang Pasien ke Poliklinik Spesialis RSI Ibnu Sina Padang}

Citra Yarsi dan RSI Ibnu Sina Padang yang bersih dan baik dimata masyarakat dan sudah lama dikenal masyarakat mempengaruhi minat berkunjung pasien ke Poliklinik Spesialis RSI Ibnu Sina, sedangkan untuk keunikan atau perbedaan citra Yarsi dan RSI Ibnu Sina Padang sebagai rumah sakit Islam merupakan faktor yang belum menonjol diantara ketiga faktor citra merek tersebut.

Brand image atau citra merek rumah sakit dalam benak pasien yang terdiri dari corporate image, user image, dan product image akan meningkatkan minat pasien untuk kembali memanfaatkan pelayanan. $15,16,17$

Citra konsumen yang positif terkait merk suatu rumah sakit akan semakin meningkat dengan semakin bertambah pengalaman pasien ketika memanfaatkan pelayanan di poliklinik spesialis RSI Ibnu Sina Padang.

\section{Persepsi Nilai Terhadap Minat Berkunjung Ulang Pasien ke Poliklinik Spesialis RSI Ibnu Sina Padang}

Persepsi nilai adalah sebuah prefensi personal, secara esensial subyektif, yang memungkinkan sebuah bisnis untuk menarik seorang konsumen dari kompetitor, nilai mungkin adalah konstruk evaluatif primer dari sebuah perspektif manajerial karena hal itu merupakan basis bagi pembuatan keputusan konsumen dalam sebuah konteks pemasaran.

Indikator paling dominan dari persepsi nilai yang dirasakan oleh pasien terhadap pelayanan poliklinik spesialis RSI Ibnu Sina Padang adalah tidak adanya penambahan biaya paket BPJS Kesehatan selama pengobatan sebesar $79,4 \%$, pasien juga merasakan bahwa manfaat pelayanan pengobatan yang diterima seimbang dengan uang yang dikeluarkan untuk membayar iuran paket BPJS Kesehatan setiap bulannya sebesar $77,1 \%$. Tetapi secara keseluruhan pelayanan belum dinilai tinggi oleh pasien, terdapat $32,3 \%$ pasien menilai biasa saja dan tidak setuju terhadap nilai dari pelayanan yang dirasakan di poliklinik spesialis RSI Ibnu Sina Padang.

Persepsi nilai merupakan penilaian konsumen secara keseluruhan terhadap kegunaan suatu produk atau jasa berdasarkan persepsi atas apa yang telah didapat. Nilai merupakan ikatan yang kuat pada persepsi konsumen atas manfaat yang dipersepsikan pelanggan (perceived value). ${ }^{18}$

Nilai yang dirasakan (perceived value) juga digunakan oleh konsumen untuk mempertimbangkan berbagai aspek layanan dengan biaya yang ditawarkan oleh beberapa perusahaan. ${ }^{19,20,21}$

\section{Persepsi Kualitas Terhadap Minat Berkunjung Ulang Pasien ke Poliklinik Spesialis RSI Ibnu Sina Padang}

Persepsi kualitas pelayanan terhadap RSI Ibnu Sina Padang dan Poliklinik Spesialis RSI Ibnu Sina Padang dinilai tinggi sebesar 69,8\%, persepsi terhadap kualitas pelayanan yang diberikan oleh tenaga pemberi pelayanan (dokter spesialis dan tenaga perawat) sangat berkualitas tinggi sebesar $64,8 \%$, persepsi pasien terhadap konsistensi tenaga pemberi pelayanan (dokter spesialis dan tenaga perawat) sangat baik sebesar $64,6 \%$, dan persepsi pasien terhadap kualitas yang dimiliki oleh poliklinik spesialis RSI Ibnu Sina Padang berbeda dengan rumah sakit lainnya sebesar $64,9 \%$. Persepsi pasien terhadap kualitas pelayanan di poliklinik spesialis RSI Ibnu Sina Padang paling baik adalah terhadap dokter spesialis/subspesialis, artinya minat pasien berkunjung ulang ke poliklinik spesialis RSI Ibnu Sina Padang karena nama besar dokter spesialis/subspesialis.

Kualitas yang dihasilkan dari pelayanan poliklinik spesialis di RSI Ibnu Sina Padang bernilai positif bagi pasien yang telah memanfaatkan layanannya. Dalam hal ini kualitas yang dinilai baik berasal dari pelayanan dokter spesialis/subspesialis yang dimiliki poliklinik spesialis RSI Ibnu Sina Padang, pasien melihat keseluruhan kualitas atau keunggulan pelayanan yang diberikan sesuai dengan yang diharapkan.

Tingkat ketergantungan yang cukup tinggi dapat mempengaruhi kinerja pelayanan yang 
diberikan. Pasien memilih rumah sakit sebagai sarana pengobatan karena alasan pelayanan, dan responden setuju terhadap kinerja pelayanan yang diterima dan telah dirasakansecara keseluruhan meskipun didasari dengan persepsi yang lebih variatif, selain itu pasien juga merasa puas dan loyal sebagai pengguna jasa layanan. $^{22}$

\section{Analisis Faktor Yang Paling Dominan Mempengaruhi Minat Berkunjung Ulang Pasien ke Poliklinik Spesialis RSI Ibnu Sina Padang}

Hasil Regression Weights Analisis nilai Estimate, Standar Error, Critical Ratio dan Probabilitas berdasarkan hasil uji hipotesis maka didapatkan faktor yang paling dominan terhadp minat berkunjung ulang pasien ke poliklinik spesilis RSI Ibnu Sina Padang adalah variable persepsi kualitas.

Pengujian keempat variabel diatas membuktikan bahwa faktor persepsi kualitas merupakan faktor yang paling dominan menentukan tingkat minat pasien untuk berkunjung ulang ke poliklinik spesialis RSI Ibnu Sina Padang. Dilihat dari hasil matrik kovarian atau matrik korelasi antara persepsi kualitas dengan minat berkunjung ulang pasien ke poliklinik spesialis RSI Ibnu Sina Padang, indikator pelayanan rumah sakit memiliki kelebihan dibandingkan rumah sakit lainnya (PQ16) memiliki korelasi positif dan kuat terhadap minat pasien untuk memilih poliklinik spesialis RSI Ibnu Sina Padang sebagai tempat berobat (PI17) (kovarian $=1,740)$. Pelayanan yang berkualitas tinggi yang dimiliki oleh poliklinik spesialis di RSI Ibnu Sina Padang memiliki korelasi positif dan kuat terhadap alasan pasien untuk menggunakan rumah sakit ini sebagai sarana pengobatan dengan akan, mengajak dan tetap menggunakan pelayanan di polikınik spesialis RSI Ibnu Sina Padang (PI19) (kovarian = 1,732). Faktor yang mendominasi pada indikator ini adalah penilaian kualitas terhadap dokter spesialis/subspesialis.

Persepsi kualitas pasien terhadap pelayanan rumah sakit keseluruhan dinilai berkualits tinggi (PQ13) terhadap keinginan pasien memilih poliklinik spesialis RSI Ibnu Sina Padang sebagai tempat berobat, memiliki nilai kovarian hanya sebesar 0,895 artinya memiliki hubungan yang positif tetapi tidak kuat. Indikator lainnya yang memiliki korelasi positif tetapi kurang kuat adalah pelayanan rumah sakit memiliki kualitas yang sangat tinggi (PQ14), sehingga pasien tidak terlalu merekomendasikan kepada orang lain untuk memiliki pelayanan di RSI Ibnu Sina Padang (PI18) (kovarian = 0,977).

Kepuasan pasien mempengaruhi kualitas layanan pada loyalitas konsumen. Pelanggan memutuskan untuk loyal terhadap suatu jasa karena mereka merasakan pelayanan yang diberikan kepada mereka tidak hanya sesuai kebutuhan tetapi juga memuaskan dan menyenangkan. Jenis pelayanan ini dalam dunia pemasaran disebut dengan pelayanan prima (excellent service) yang selalu diharapkan pelanggan. ${ }^{23}$

Kualitas pelayanan berpengaruh positif terhadap kepuasan pasien, dan kepuasan pasien memediasi pengaruh kualitas pelayanan pada loyalitas pasien. Ketika seorang pasien memiliki kesan yang baik tentang suatu pelayanan rumah sakit, maka akan meningkatkan kepuasan pasien, sehingga pasien cendrung berminat kembali berkunjung untuk menggunakan jasa dari rumah sakit tersebut serta merekomendasikannya kepada orang lain. ${ }^{24}$

Kualitas layanan yang baik diberikan oleh perusahaan akan memperoleh keunggulan kompetitif yang berkelanjutan. Dengan memberikan pelayanan yang berkualitas, tentu akan menjadi nilai lebih sendiri baik dari segi pasien kepada rumah sakit maupun rumah sakit dengan pesaingnya. Upaya memberikan pelayanan yang berkualitas pada pasien memicu pasien untuk kembali memanfaatkan pelayanan pada rumah sakit tersebut. ${ }^{25}$

Keberhasilan rumah sakit dalam memberikan layanan kesehatan yang sesuai dengan standar pelayanan kesehatan kepada para pasiennya telah menumbuhkan loyalitas pasien. Orientasi pada kualitas pelayanan, rumah sakit akan mampu mendapatkan profitabilitas jangka panjang yang diperoleh dari kepuasan pasien. Kondisi demikian membuat rumah sakit harus mulai merubah pola pikir ke arah pemikiran yang berfokus pada patient oriented sebagai satu tujuan dari program kepuasan pasien dan harus mempunyai pemahaman dan pengertian yang lebih baik tentang pentingnya kepuasan dan loyalitas pasien. Loyalitas pasien akan terbentuk 
dengan sendirinya apabila rumah sakit mampu meningkatkan kualitas layanan yang diberikan, sehingga hubungan jangka panjang antara pasien dan rumah sakit akan terbentuk. ${ }^{26}$

\section{SIMPULAN}

Manajemen RSI Ibnu Sina Padang belum menentukan segmentasi pasien, target dan positioning, perbaikan penilaian oleh sikap pasien, memperbaiki dan mempertahankan citra merek, memperbaiki nilai yang dirasakan pasien terhadap pelayanan, perbaikan kualitas pelayanan yang diberikan rumah sakit dan tenaga pemberi pelayanan, serta melakukan upaya peningkatan minat pasien dengan melakukan promosi, perbaikan fasilitas sarana prasarana, dan peningkatan mutu pelayanan. Implikasi yang dilakukan adalah dengan mengaktifkan unit yang ada dalam manajemen, melibatkan masyarakat sekitar, peranan yayasan, peranan dokter spesialis/ subspesialis, perbaikan faktor-faktor yang mempengaruhi minat berkunjung pasien, pembenahan kondisi internal dan ekternal rumah sakit.

\section{DAFTAR PUSTAKA}

1. Undang Undang Republik Indonesia No 44 tahun 2009 tentang rumah sakit. Jakarta: Sekretariat Negara; 2009.

2. BPJS Kesehatan. Badan penyelenggara jaminan sosial (diakses tanggal 2 April 2018). Tersedia dari: http://www.bpjs-kesehatan.go.id/bpjs/

3. RSI Ibnu Sina. Profil RSI Ibnu Sina Padang tahun 2017. Padang: RSI Ibnu Sina; 2018

4. Jessica PS, Sifrid SP, Maria VJ, Tielung. Analyzing the effect of word of mouth and consumer attitude on purchase intention At Siloam Hospital Manado. Jurnal Berkala IImiah Efisiensi. 2017;17(01):53-63.

5. Morteza S, Mohammad RE, Gholamreza J, Nima $S$. The effect of service quality on private brand image and purchase intention in the chain stores of ETKA. World Scientific News, 2016 ; Volume 47(2), EISSN 2392-2192 : 202-216

6. Jing L, Jiang L, Youngbiao Z. Corporate image cognition influence perceived quality and purchase intention empirical research. Journal iBusiness. 2013;5:162-7.
7. Ferdinand A. Structural equation modeling dalam penelitian manajemen. Semarang: Badan Penerbit Universitas Diponegoro; 2006.hlm.76-97

8. Hair JF, Anderson RE, Tatham RL, Black WC. Multivariate data analysis. Edisi ke-5. New Jersey: Upple Saddle River: Prentice Hall; 2006. hlm.32040.

9. Zailani S, Ali SM, Iranmanesh M, Moghavvemi S, Musa G. Predicting muslim medical tourists' satisfaction with Malaysian Islamic Friendly Hospitals. Tourism Management. 2016;57:159-67.

10. Zailani S, Iranmanesh M, Aziz AA, Kanapathy K. Halal logistics opportunities and challenges. Journal of Islamic Marketing. 2017;8(1):127-39.

11. Kotler P, Kevin LK. Manajemen pemasaran Jilid 1. Edisi ke-12. Jakarta: PT Indeks; 2009.hlm.5.

12. Rini ES. Pengaruh brand image terhadap perceived value pelanggan di STIKOM Bali. Jurnal sistem dan Informatika. 2017;11(2):110-9.

13. Mohajerani P. Costumer satisfication modelling in hotel industry. a case study of Kish Island in Iran. International Journal Of Marketing Studies. 2012;4 (3):134-52.

14. Aghekyan-Simonian M, Forsythe S, Kwon WS, Chattaraman $\mathrm{V}$. The role of product brand image and online store image on perceived risks and online purchase intentions for apparel. Journal of Retailing and Consumer Services. 2012;19:325-31.

15. Oktariany N, Marwati T, Rosyidah. Hubungan antara brand image dengan minat pasien untuk berobat di poliklinik anak rumah sakit PKU Muhammadyah Yogyakarta. Jurnal Kesehatan Masyarakat. 2011;5(3):162-232.

16. Priyono E, Haryono AT, Minarsih MM. Analisis pengaruh citra merek, strategi promosi, atribut produk, harga terhadap minat berkunjung serta pengaruhnya terhadap minat beli. Journal Of Managemen. 2016;2(2):1-22.

17. Yulistia RA, Haerudddin. Pengaruh kualitas layanan dan citra terhadap kepuasan dan minat kembali untuk memanfaatkan pelayanan di instalasi rawat inap rumah sakit umum daerah Haji Makassar tahun 2017. Jurnal Imiah Kesehatan Diagnosis. 2017;11(4):429-33. 
18. Kotler P, Gary A. Prinsip-prinsip pemasaran Jilid 1. Edisi ke-13. Jakarta: Penerbit Erlangga; 2012. hlm.196.

19. Hansudoh, Steven A. Pengaruh celebrity endorsement terhadap purchase intention melalui perceived value pada produk top coffee di Surabaya. Journal Universitas Katolik Widya Mandala Surabaya. 2012;1(05):1-7.

20. Hsin HC, Hsin-Wei W. The moderating effect of customer perceived value on online shopping behaviour. Online Information Review. 2011;35(3): 333-59.

21. Ho HY, Lin PC, Lu MH. Effects of online crowdfunding on consumers perceived value and purchase intention. Journal Anthropologist. 2014; 17(3):837-44

22. Andri G. Pengaruh kinerja pelayanan RS Islam Ibnu Sina dan kepuasan pasien sebagai variabel moderator terhadap loyalitas pasien pada RS Islam Ibnu Sina di Sumatera Barat. Jurnal Manajemen dan Kewirausahaan. 2011;2(2):58-75.
23. Siti NJ, Pan EL, Mohaini MN. Consumer's perceptions, attitudes and purchase intention towards private label food products in Malaysia. Asian Journal of Business and Management Sciences. 2012;2(8):73-90.

24. Sibarani T, Riani AL. The effect of health service quality and brand image on patients loyalty, with patients satisfaction as mediating variable (a study in VIP ward of Prof. Dr. R. Soeharso Ortopedics Hospital in Surakarta). Sebelas Maret Review. 2017;2(1):25-42.

25. Jelcic S. Managing service quality to gain competitive advantage in retail environment. TEM Journal. 2014;3(2):181-6.

26. Suryaningrat D. Hubungan kualitas pelayanan terhadap loyalitas pasien melalui kepuasan sebagai variabel intervening dalam pelayanan kesehatan (studi kasus di rumah sakit Yarsi Pontianak). Jurnal IImiah Ibnu Sina. 2018; 3 (1): 115-24. 